\title{
Clinical Results of Median Corpectomy in Cervical Spondylotic Patients with Myelopathy
}

\author{
Ismail ISTEMEN ${ }^{1}$, Selcuk OZDOGAN², Ali Haluk DUZKALIR ${ }^{3}$, Salim SENTURK ${ }^{4}$, Timur YILDIRIM ${ }^{5}$, \\ Mehmet Ozerk OKUTAN ${ }^{6}$
}

${ }^{1}$ Güney Adana Hospital, Adana, Turkey

${ }^{2}$ Yeditepe University, School of Medicine, Department of Neurosurgery, Istanbul, Turkey

${ }^{3}$ Zonguldak Ataturk State Hospital, Zonguldak, Turkey

${ }^{4}$ Hitit University, Corum Education and Research Hospital, Corum, Turkey

${ }^{5}$ Ordu University, School of Medicine Department of Neurosurgery, Ordu, Turkey

${ }^{6}$ Medicana Hospital, Konya,Turkey

\section{ABSTRACT}

AIM: To determine the factors in choosing the right surgical technique for patients with cervical spondylotic myelopathy.

MATERIAL and METHODS: 60 patients were operated with anterior median corpectomy and anterior fusion for cervical myelopathy in Ankara Atatürk Education and Research Hospital between the years 2006-2011. All data were obtained from patient files retrospectively. Patients were evaluated in the preoperative and early postoperative stages and 45 days after discharge by referring to their neurological examinations, Japanese Orthopaedic Association (JOA) and Nurick scores and radiological findings.

RESULTS: The average age of the patients was $53.8 \pm 9.9$ years (38-78) and 45 were male (75\%) and 15 were female $(25 \%)$. Diabetics made up $16.7 \%(n=10)$ of the group and nondiabetics $83.3 \%(n=50)$. Of the nondiabetic patients, the Nurick score on the first month after surgery was statistically lower than the preoperative and after 24 hours Nurick score $(p<0.001)$. In the patients in the group that had 1 or 2 myelopathic findings, the Nurick score on the first month after surgery was statistically lower than the preoperative and after 24 hours Nurick score $(p<0.001)$. The JOA score one month after surgery was statistically lower in patients with myelomalacia than in patients without myelomalacia $(\mathrm{p}=0.002)$.

CONCLUSION: Median corpectomy and anterior fusion technique had better scores in patients that had few and early myelopathic symptoms, no myelomalacia on MRI, and no systemic disease.

KEYWORDS: Anterior cervical fusion, Cervical spondylosis, Median corpectomy, Myelopathy

\section{INTRODUCTION}

Cervical spondylosis is a progressive and degenerative condition that starts from the intervertebral disc and continues with the hypertrophy of osseous and connective tissue surrounding the spinal canal (20). Cervical spondylotic myelopathy (CSM) is a neurologic disorder resulting from chronic compression of medulla spinalis and nerve roots in the spinal canal that has been narrowed down due to spondylosis $(36,39)$. CSM is the most frequent cause of acquired spastic paraparesis and myelopathy in the advanced age group $(11,26)$. CSM results in serious loss of function in the elderly and consumption of health resources. Misdiagnosis of this condition has decreased substantially as direct radiography, computerized tomography (CT) and magnetic resonance imaging (MRI) are used more widely. However, there is no consensus on the optimal treatment. Discussion is focused on whether the treat- 
ment should be surgical or conservative, and whether the posterior or anterior approach should be chosen in surgical treatment $(7,21,23,28,32)$.

We aimed to compare the clinical and radiological findings of patients who underwent anterior corpectomy and fusion due to cervical spondylosis in our clinic.

\section{MATERIAL and METHODS}

Sixty patients who were operated for cervical myelopathy between 2006-2011 in Ankara Atatürk Education and Research Hospital $1^{\text {st }}$ Neurosurgery clinic were evaluated retrospectively. Demographical, clinical and radiological data were obtained from patient files. Patients with cervical canal stenosis and consequent myelopathy caused by mass, abscess, spondylosis and ossified posterior longitudinal ligament (PLL) were included in this study. Myelopathic symptoms were defined by physical examination and clinical findings such as decrease in manual dexterity, inability to standup without support, walking problems, inability to discern hot or cold, sensory disorders or sphincter problems $(9,25)$. Myelomalacia was defined and added to to study by T2 signals on spinal cord in sagittal images of MRI. Exclusion criteria were follow-up period less than 6 months, patients who underwent posterior decompression (indication for posterior approach was compression on posterior elements by ligament or mass without anterior compression), patients who were operated in the early period following trauma, and patients who had an additional neurological disease (multiple sclerosis, amyotrophic lateral sclerosis etc.). Age, severity of complaints, preoperative neurological examination and radiological data (MRI, $\mathrm{CT}$, direct radiography) were taken into consideration when deciding for surgery. All patients in the study had undergone median corpectomy and anterior fusion with the anterior approach. A transverse incision was used for all patients. Neurological findings, JOA scores, Nurick scores and radiological findings of the patients prior to operation were evaluated in the early postoperative period and on the $45^{\text {th }}$ postoperative day.

\section{Surgical Technique}

Patients with advanced myelopathy and stenotic canal were intubated using fiberoptic bronchoscopy since hyperextension of the neck could exacerbate the existing neurological condition. The remaining patients were intubated using neuromuscular blockers in a standard manner avoiding forced movements. The head was positioned neutrally with the neck in mild extension. Both arms were tracted downwards from the shoulders in order to use fluoroscopy. The localization of the skin incision was determined using anatomical landmarks for reference points with fluoroscopy. These landmarks were as follows:

\section{C1-2 level: Angle of the mandible}

C3-4 level: $1 \mathrm{~cm}$ above thyroid cartilage (hyoid bone)

C4-5 level: Thyroid cartilage

C5-6 level: Cricothyroid membrane

\section{C6 level: Carotid tubercle}

\section{C6-7 level: Cricoid cartilage}

A transverse skin incision was made and adjusted for the level of planned corpectomy. The skin was liberated from subcutaneous tissue in order to provide adequate space following skin incision. The platysma was incised longitudinally and a subplatysmal dissection was carried out to obtain a wider surgical area. The prevertebral space was reached following the blunt dissection of the sternocleidomastoideus muscle with the carotid artery laterally and oesophagus and trachea medially. The level of corpectomy was identified using fluoroscopy and the sides of longus colli muscles attached to the vertebral corpi were incised 3-4 $\mathrm{mm}$ laterally using bipolar coagulation. Retractors were placed after reaching the desired level. Retractors were periodically released in order to avoid compression of the recurrent laryngeal nerve between the trachea and the retractors. Microdiscectomy was carried out on the upper and lower level discs of the level of corpectomy. Corpectomy was carried out using a drill until PLL was reached. Cartilaginous surfaces of the upper and lower end plates of neighboring vertebrae were cleaned following corpectomy. Then, the lower and upper end plates were rendered parallel and neighboring verteral corpi were decorticated in order to prepare them for grafting. Since complete conformity of the graft and the vertebra corpus increases the area of fusion, complete contact of end plates with the graft and the preservation of the vertebral axis were confirmed.

Criteria such as structural strength, antigenic match, fast knitting, complications of graft location, and easy application were considered in choosing the graft that was applied to the corpectomised area. lliac crest graft, fibula graft, distractable cage systems and plate cage systems were applied to patients with filling using autologous bone fragments, bone chips or putty. The length of the graft was measured without placing traction on the head and it was placed to the gap while traction was applied to the head. A tight fitting contact between the graft and the neighboring vertebral corpus was achieved. A titanium anterior cervical plate system was chosen because this system increases the fusion ratio, avoids deformities, decreases the risk of anterior dislocation of the graft, and decreases the stress on the graft, thus preventing graft collapse. During plate placement, upper screws were directed cranially and medially and the lower screws were directed caudally and medially while avoiding contact with the lower and upper disc space. These interventions were carried out in order to avoid malposition of the screws. Length of the screws was selected so that they would not protrude beyond the posterior wall of the corpus. Operations were ended after checking with fluoroscopy. Selections from postoperative results have been presented with figures (Figures 1-4).

\section{Statistical Analysis}

Patient demographics were summarized using basic statistics. Average, standard deviation, median, minimum and maximum values were used in the summarization of qualitative values while numbers and percentages were used for categorical 

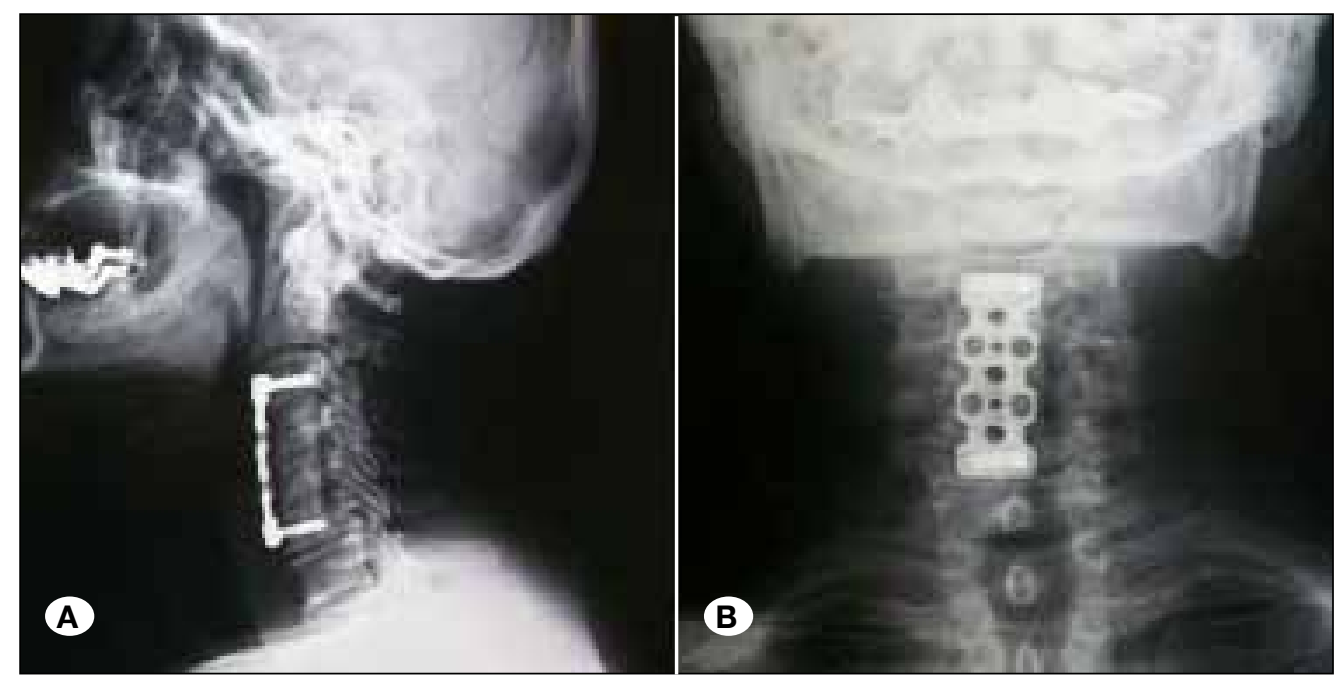

Figure 1: Lateral (A) and anteroposterior (B) X-ray views of C 4-5 corpectomy and fusion with fibula graft and anterior plate.

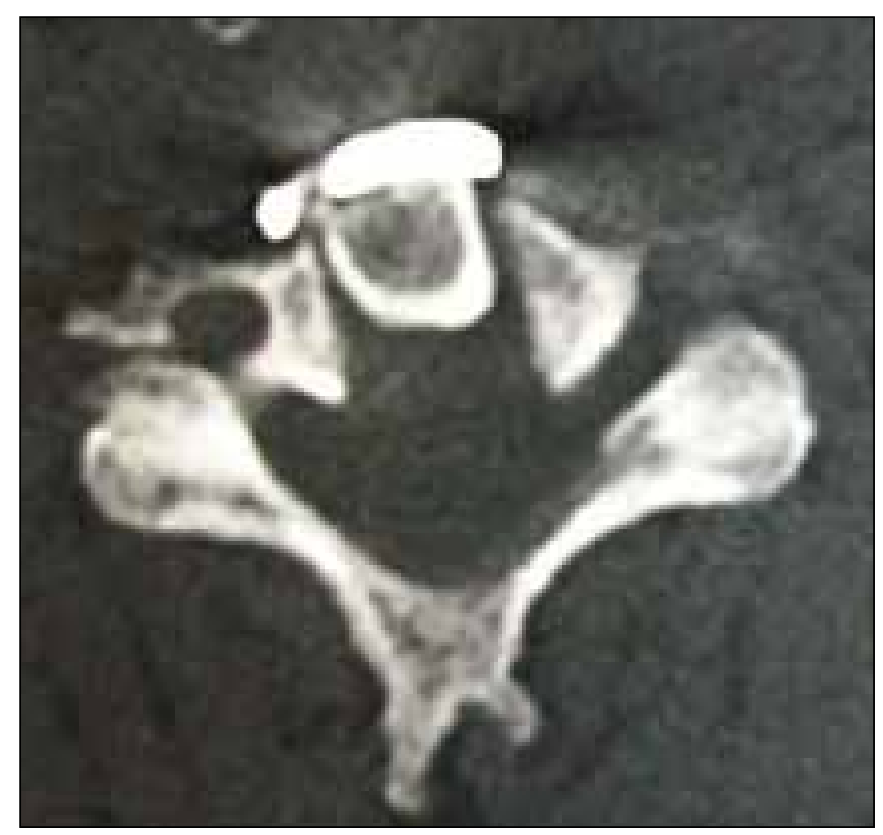

Figure 2: Computed tomography axial view of corpectomy and fusion with fibula graft and anterior plate.

variables. Statistical significance $(p)$ was set at 0.05 . The Bonferroni adjustment was used for multiple comparisons and statistical significance was set at 0.016 . Statistical analyses were carried out using SPSS v16.0. The KolmogorovSmirnov test was used to evaluate the distribution of all variables in secondary comparisons and non-parametric statistical methods were used for variables with a non-normal distribution. The Kruskall-Wallis test was used for groups with 3 variables while the Mann-Whitney $U$ test was used for groups with 2 variables. The Friedman variance analysis was used to analyse the changes in JOA and Nurick scores over time and the Wilcoxon test was used for multiple comparisons. Crosstable statistics (Chi squared, McNemar, Kappa) were used for comparison of categorical variables.

\section{RESULTS}

The average age of patients in the study was $53.8 \pm 9.9$ (38$78)$. There were 45 male patients $(75 \%)$ and 15 female patients (25\%). Diabetic patients made up $16.7 \%$ of the patients $(n=10)$ and nondiabetics $83.3 \%$.

\section{Distribution of Stenotic Levels in MRI}

18 patients had stenosis on $\mathrm{C} 5-\mathrm{C} 7$ and 1 patient had stenosis on C6-T1 levels on MRI.

\section{Distribution of Stenotic Levels in CT}

$28.3 \%$ of the patients had stenosis at C5-C7 levels in CT while $11.7 \%$ patients did not have CT results.

\section{Instrumentation Methods Applied to Patients}

The Fibula+plate method was applied to $58.3 \%(n=35)$ of the patients.

\section{Comparison of JOA Scores for Myelomalacia}

Preoperative and $24^{\text {th }}$ hour JOA scores were similar between patients with or without myelomalacia $(p<0.05)$ while this score was significantly lower in patients with myelomalacia at the end of the first month $(p=0.002)$. The JOA score was 13.58 \pm 1.96 in the preoperative period while it was $13.98 \pm 1.80$ at the $24^{\text {th }}$ hour in patients without myelomalacia. This change was found to be significant $(p<0.001)$. The JOA score average was $15.88 \pm 1.54$ at the end of the first month. This increase in the first month when compared to the preoperative and first 24 hour values was found to be statistically significant.

In patients with myelomalacia, the JOA score was $13.53 \pm$ 1.50 in the preoperative period, $14.00 \pm 1.49$ at the $24^{\text {th }}$ hour and $15.00 \pm 1.37$ at the end of the first month. The JOA score at 24 hours was significantly higher than the preoperative JOA score $(p<0.001)$. The JOA score at the end of the first month was significantly higher than the preoperative and $24^{\text {th }}$ hour JOA score $(p<0.001)$.

\section{Comparison of Nurick Scores for Myelomalacia}

In patients without myelomalacia, the Nurick score was 1.80 

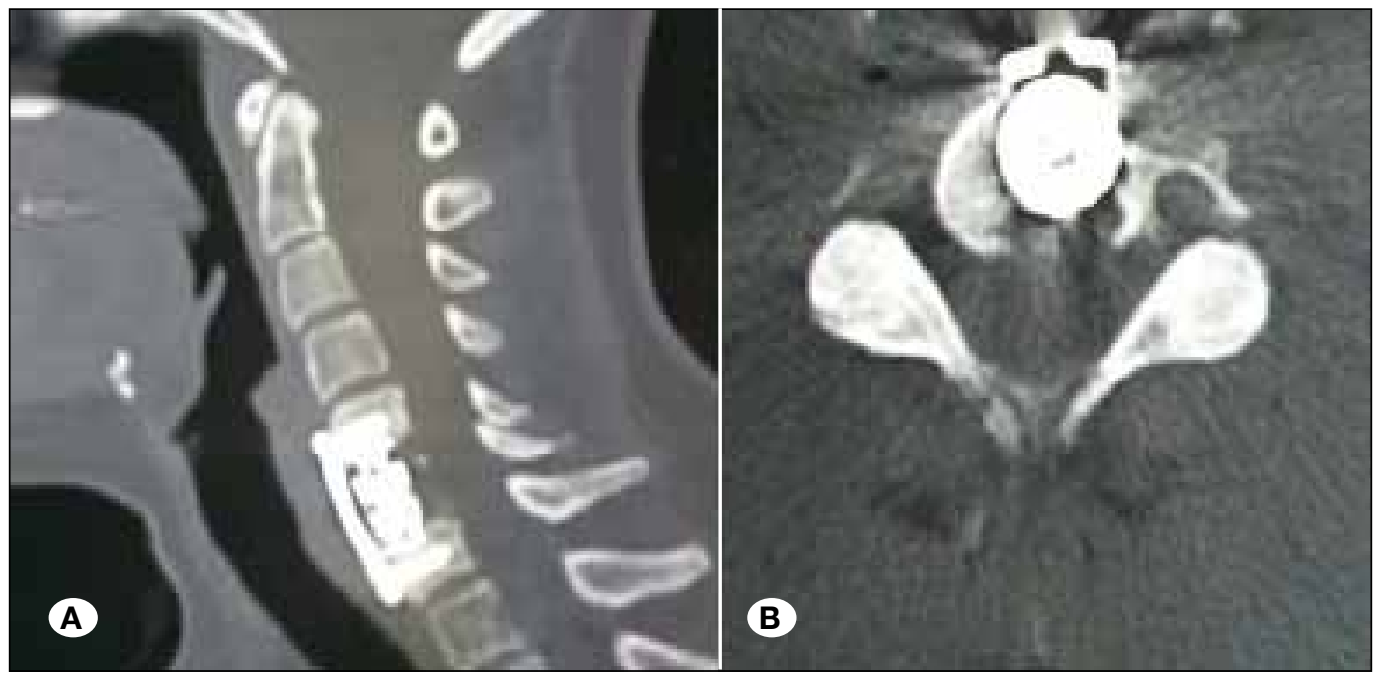

Figure 3: Sagittal (A) and axial (B) Computed tomography view of $\mathrm{C} 6$ corpectomy and fusion with interbody cage.

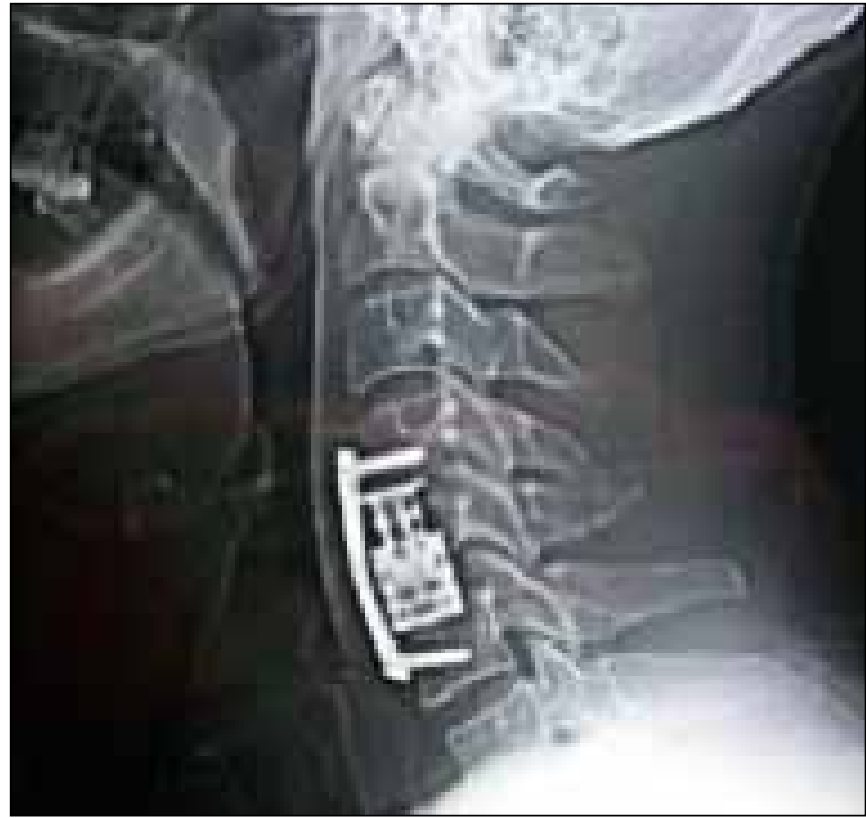

Figure 4: Lateral X-ray of C5 corpectomy and fusion with interbody cage.

\pm 0.81 in the preoperative period, $1.68 \pm 0.79$ in the first 24 hours and $1.21 \pm 0.54$ at the end of the first month. In patients without myelomalacia, the Nurick score at the end of the first month was significantly lower than the score at 24 hours and the preoperative period $(p<0.016)$. The preoperative Nurick score was similar to the Nurick score at 24 hours $(p=0.025)$. In patients with myelomalacia, the Nurick score was $1.74 \pm$ 0.65 in the preoperative period, $1.68 \pm 0.79$ at the $24^{\text {th }}$ hour and $1.37 \pm 0.60$ at the end of the first month. Nurick scores were similar for patients with myelomalacia in these periods ( $p>0.05)$.

\section{Concordance Between MRI and CT}

In stenosis of one level, MRI and CT showed full concordance while there was a statistically significant difference when
2 or 3 levels of stenosis were existent $(p=0.011)$. The level of concordance between two imaging methods was $73 \%$ (Kappa=0.733).

\section{Comparison of Nurick Scores for Corpectomy Levels}

While the $24^{\text {th }}$ hour Nurick scores of patients with only one level of corpectomy was lower than the preoperative Nurick score $(p=0.014)$, no difference was observed in these periods for patients with two levels of corpectomy $(p=0.1577)$. In patients with two levels of corpectomy, the Nurick score at the end of the first month was significantly lower than the preoperative Nurick score $(p<0.001, p<0.001$ respectively). Nurick scores of patients with only one level of corpectomy at the end of the first month was significantly lower than Nurick scores at 24 hours $(p=0.004)$. The nurick scores at the end of the first month of patients with two levels of corpectomy was lower than the Nurick scores at 24 hours and this difference was statistically significant $(\mathrm{p}=0.001)$

\section{Comparison of JOA Scores for Corpectomy Levels}

JOA scores were similar between groups when compared according to number of levels corpectomy was performed $(p>0.05)$. When JOA scores were compared or changes in time, JOA scores at 24 hours of patients with 1 or 2 levels of corpectomy were significantly higher than preoperative JOA scores $(p<0.001$ and $p=0.001$ respectively). JOA scores at the end of the first month are significantly higher than preoperative JOA scores of patients with 1 or 2 levels of corpectomy $(p<0.001)$. Similarly, when JOA scores at 24 hours and JOA scores at the end of the first month are compared, the latter was found to be significantly higher than the former $(p<0.001)$.

\section{Comparison of JOA Scores for Gender}

JOA scores at the preoperative period, 24 hours and the first month are similar when compared for gender $(p>0.05)$. JOA scores at 24 hours were higher than preoperative JOA scores for male patients $(p<0.001)$ while these scores were similar for female patients $(p=0.025)$. JOA scores at the end of the first month were significantly higher than preoperative and 24 hour scores for both male and female patients $(p<0.001)$ 


\section{Comparison of Nurick Scores for Gender}

Nurick scores were similar at all three measurement points when compared for gender ( $p>0.05)$. Nurick scores at 24 hours were significantly lower than preoperative Nurick scores for male patients $(p=0.005)$ while these scores were the same at these measurement points for female patients $(p=1.000)$. Nurick scores at the end of the first month were significantly lower than scores at $24^{\text {th }}$ hour and the preoperative period $(p=0.001$ and $p=0.008$ respectively)

\section{Comparison of JOA scores for Age Groups}

The median age of patients enrolled in the study was 53.8 years. There was no difference between JOA scores of patients below 54 or above 54 years ( $p>0.05$ ). When preoperative and $24^{\text {th }}$ jour JOA scores were compared, a statistically significant increase was observed, regardless of age $(p=0.001)$. JOA scores at the end of the first month were significantly higher than the preoperative and $24^{\text {th }}$ hour JOA scores in both age groups $(\mathrm{p}<0.001)$

\section{Comparison of Nurick Scores for Age Groups}

There were no statistically significant differences between age groups for Nurick scores ( $p>0.05$ ). Nurick scores at the end of the first month were significantly lower than preoperative and $24^{\text {th }}$ hour Nurick scores in both age groups $(p=0.002)$

\section{Comparison of Nurick Scores for Diabetes Mellitus (DM)}

There were no statistically significant differences in Nurick scores between DM positive and negative patients $(p>0.05)$. Nurick scores at 24 hours were significantly lower than preoperative scores in patients without DM $(p=0.005)$ while these values were similar in patients with DM $(p=1.000)$. Nurick scores at the end of the first month were significantly lower than preoperative and $24^{\text {th }}$ hour Nurick scores in patients without DM $(p<0.001)$ while there were no statistically significant changes in DM positive patients at the end of the first month compared to preoperative and $24^{\text {th }}$ hour scores $(p=0.046)$

\section{Comparison of JOA Scores for DM}

There were no statistically significant differences in JOA scores of DM positive and negative patients ( $p>0.05)$. Preoperative JOA scores were lower than $24^{\text {th }}$ hour and first month JOA scores and $24^{\text {th }}$ hour JOA scores were lower than first month JOA scores in DM negative patients $(p<0.001)$. There were no statistically significant changes between preoperative and $24^{\text {th }}$ hour JOA scores $(p=0.083)$ while JOA scores at the end of the first month were significantly higher than preoperative and $24^{\text {th }}$ hour JOA scores in DM positive patients $(p=0.005)$.

\section{Myelopathic Symptoms in Patients}

We found that $78.3 \%$ of the patients enrolled in the study had deterioration of hand function, $60 \%$ had walking dysfunction, $28.3 \%$ could not stand up without support and $13.3 \%$ had problems with hot-cold discernment.

\section{Distribution of Myelopathic Symptoms in Patients}

Six of the 60 patients had no myelopathic symptoms while
21 patients had 2, 18 patients had 1, 13 patients had 3 and 2 patients had 4 myelopathic symptoms.

\section{Comparison of JOA Scores for Myelopathic Findings}

The patients were grouped as no myelopathic findings, 1-2 myelopathic findings or 3-4 myelopathic findings. There were no statistically significant differences in JOA scores of patients with 3-4 myelopathic findings $(p>0.05)$. Preoperative JOA scores of patients with no or 1-2 myelopathic findings were significantly lower than $24^{\text {th }}$ hour and first month JOA scores $(p<0.001)$. JOA score at the end of the first month were significantly higher than $24^{\text {th }}$ hour JOA scores in the same patients $(p<0.001)$. In patients with 3-4 myelopathic findings, preoperative JOA scores were significantly lower than $24^{\text {th }}$ hour JOA scores $(p=0.014)$ and first month JOA Scores $(p=0.005)$. The JOA score at the end of the first month was significantly higher than $24^{\text {th }}$ hour JOA scores in the same patient group $(\mathrm{p}=0.013)$.

\section{Comparison of Nurick Scores for Number of Myelopathic Findings}

There were no statistically significant differences in Nurick scores for number of myelopathic findings ( $p>0.005)$. In patients with less than 3-4 myelopathic findings, preoperative Nurick score was significantly higher than $24^{\text {th }}$ hour Nurick score $(p=0.014)$. The Nurick score at the end of the first month was significantly lower than preoperative and $24^{\text {th }}$ hour Nurick scores in this group $(p<0.001)$. In patients with $3-4$ myelopathic findings, there were no statistically significant changes in Nurick scores $(p=0.066)$.

\section{DISCUSSION}

Cervical spondylosis is a condition that starts at the intervertebral disc and continues in the neighboring bone and soft tissue (20). The intervertebral disc space gets gradually smaller with the natural aging process. Diffuse bulging and overflow of the disc are results of this process. When hypertrophy of ligaments (PLL, ligamentum flavum) accompanies osteophyte formation and arthritic changes in the facet and uncovertebral joints, a circular stenosis of the spinal canal ensues $(30,35)$. The stenosis causes compression of the medulla spinalis and nerve roots and results in myelopathy.

The choice of surgical technique in this situation is still a matter of debate (27). Different success rates for anterior and posterior approaches have been reported in the literature $(4,10,12,14)$. Corpectomy and fusion abolishes the compression effect and corrects the sagittal deformity in cases with deformed cervical lordosis, kyphotic deformities and stenosis in less than 3 levels $(15,33,37)$. Naderi et al. have stated that the age of the patient, the location of compression, level and number of stenoses, existence of hyperintensity (myelomalacia) on MRI, curvature of the spine, normal range of motion and abnormal movements of the vertebrae have to be considered when deciding for surgery (28).

MRI may be the most important diagnostic intervention performed for patients with CSM (2,34). While CT can only show stenoses caused by bones, MRI can reveal 
compressions caused by soft tissue. It has been stated that high levels of T2 signals have prognostic value and patients with a hyperintense lesion in T2 exhibit a slower and less complete recovery of symptoms in the postoperative period. Low intensity signals in T1 and high intensity signals in T2 images of gray matter points to advanced lesions such as myelomalacia or necrosis $(24,40)$. In our cases, patients with myelomacia on MRI had slower and less complete recovery of the JOA and Nurick scores. A concordance level of $73 \%$ was observed when MRI and CT results were compared and MRI was found to be more successful in the determination of stenotic levels. However, CT remains an undispensable tool in treatment as it reveals whether the stenosis is caused by bone or calcified soft tissue and thus helps planning of treatment. The most frequent stenosis level was found to be $\mathrm{C} 5-\mathrm{C} 7$ $(30 \%)$ in the radiographic tests of our patients.

Spondylosis and myelopathy seem to be more prevalent in the male sex in many series. The male to female ratio was $3 / 1$ in our case. There were no statistically significant differences in the level of recovery between male and female patients when JOA and Nurick scores were compared. Lifting heavy weights, working at jobs that cause posture changes, trauma (single major or repetitive minor), excessive extension of the head, rheumatoid arthritis, mass, discitis and abscess, genetic factors, congenital and developmental deformities can be listed among predisposing factors $(1,29,38)$. However spondylosis can develop with age even when there are no predisposing factors present.

The literature shows that 3 or more levels of corpectomy for decompression increases the risk of complications with graft and/or instrumentation 2.5 fold (6). Biomechanical studies show that a graft and instrument system weakens if three or more levels of corpectomy is performed (16). The load on the plate and the graft decreases especially during flexion and this also decreases the probability of fusion (8). Placement of an anterior plate following grafting is especially advised in the literature because it increases the chance of fusion, corrects deformities and prevents the formation of new ones, acts as a barrier in front of the graft and prevents the graft from sliding anteriorly, shares the load of the graft, and prevents graft compression (8). These are the reasons that why we did not perform corpectomy on three and more levels. An anterior plate was placed in all our patients while three patients received a corpectomy cage with plate. Only one patient had to be reoperated in the early postoperative period due to posterior dislocation of the fibula graft. One patient had to be revised due to loosening of one of the plate screws one year after the first operation. Complete fusion of the graft was observed during the operation.

Vocal cord injuries, Horner syndrome and dural injuries are frequent complications for anterior approach. Vocal cord paralysis could be due to the compression of the recurrent laryngeal nerve during surgical retraction and exploration or direct compression of the vocal cords by increased cuff pressure of the endotracheal tube (5). The incidence of recurrent laryngeal nerve caused by surgery varies between 0.07 and $11 \%$ according to the literature (17). Approximately
$80 \%$ of the nerve damage recovers spontaneously in 3-4 weeks (31). One of our patients had hoarseness that spontaneously resolved in two weeks. Horner syndrome can be observed due to the lesions of superior cervical ganglion and postsynaptic nerves originating from this location following anterior approaches $(14,19)$. Patients may complain of miosis, ptosis, enophtalmos, anhydrosis and facial flushing. The incidence of Horner syndrome is $0.1-1.1 \%(5,13)$. One of our patients had Horner syndrome that resolved in one week. Dural damage as a surgical complication has been reported in $0.3-1.8 \%$ in the literature $(3,5)$. We did not observe any dural damage.

The possibility of all or more than one of these symptoms appearing increases proportionally to the duration and severity of the stenosis. This is a factor that decreases the speed and quality of recovery. Lu et al. report that anterior surgery provides adequate decompression and increases the JOA score and that this score best correlates to clinical recovery, parallel to many other studies (22). Jung-Ju et al. report that JOA scores increase in the postoperative period (18).

The JOA and Nurick scores of our patients improved in a statistically significant manner, similar to the literature. However, when we grouped the patients according to the number of myelopathic symptoms present, we observed that patients with less myelopathic symptoms showed better improvement on the postoperative JOA and Nurick scores. DM positive patients had slower recoveries than DM negative patients. The average age of our patients was 53 and when we divided our patients into younger than 53 and older than 54 , we did not observe any differences between groups according to age. There were no statistically significant differences when the patients were grouped according to whether one or two levels of corpectomy was performed.

The limitations of this study are its being retrospective instead of a randomised controlled study, relatively short follow-up periods and the low number of patients.

\section{- CONCLUSIONS}

Early results show that better outcomes can be obtained when anterior corpectomy and fusion is performed in patients with no myelomalacia on MRI, have fewer symptoms of myelopathy, and do not have DM. It has been observed that better clinical and radiologic recovery can be expected in selected patients.

\section{REFERENCES}

1. Adams RD, Victor M: Disease of the spinal cord. In: Lambsback WJ, Navrozov M (eds), Principles of Neurology (5th ed). New York: Monotype Composition, 1993:1078-1116

2. Al-Mefty $\mathrm{O}$, Harkey LH, Middleton TH, Smith RR, Fox JL: Myelopathic cervical spondylotic lesions demonstrated by magnetic resonance imaging. J Neurosurg 68:217-222, 1988

3. Barnes B, Haid RW, Rodts GE, Subach BR, Kaiser M: Early results using the Atlantis anterior cervical plate system. Neurosurg Focus 12(1):E13, 2002 
4. Benzel EC: Cervical spondylotic myelopathy posterior surgical approaches. In: Menezes AH, Sonntag VKH (ed), Principles of Spinal Surgery. New York: McGraw Hill, 1996:571-581

5. Bertalanffy H, Eggert HR: Complications of anterior cervical discectomy without fusion in 450 consecutive patients. Acta Neurochir (Wien) 99:41-50, 1989

6. Boakye M, Patil CG, Ho C, Lad SP: Cervical corpectomy: Complications and outcome. Neurosurgery 63 ONS Suppl 2:295302, 2008

7. Cusick JF: Pathophysiology and treatment of cervical spondylotic myelopathy. Clin Neurosurg 37: 661-681, 1991

8. DiAngelo DJ, Foley KT, Vossel KA, Rampersaud YR, Jansen TH: Anterior cervical plating reverses load transfer through muitilevel strut-grafts. Spine 25:783-795, 2000

9. Emery SE: Cervical spondylotic myelopathy: Diagnosis and treatment. J Am Acad Orthop Surg 9:376-388, 2001

10. Epstein JA, Carras R, Hyman RA: Cervical myelopathy caused by developmental stenosis of the spinal canal. J Neurosurg 51:362367, 1979

11. Ferguson RJL, Caplan LR: Cervical spondylotic myelopathy. Neurol Clin North Am 3: 373-382, 1985

12. Fernyhough JC, White JI, LaRocca H: Fusion rates in multilevel spondylosis comparing allograft fibula with autograft fibula in 126 patients. Spine 16 Suppl :S561-S504, 1991

13. Fountas KN, Kapsalaki EZ, Nikolakakos LG, Smisson HF, Johnston KW, Grigorian AA, Lee GP, Robinson JS Jr: Anterior cervical discectomy and fusion associated complications. Spine 32(21):2310-2317, 2007

14. George B, Gauthier N, Lot G: Multisegmental cervical spondylothic myelopathy and radiculopathy treated by multilevel oblique corpectomies without fusion. Neurosurgery 44: 81-90, 1999

15. Harrop JS, Hanna A, Silva MT, Sharan A: Neurological manifestations of cervical spondylosis: an overview of signs, symptoms, and pathophysiology. Neurosurgery 60 (Supp1 1):1420, 2007

16. Isomi T, Panjabi MM, Wang JL, Vaccaro AR, Garfin SR, Patel T: Stabilizing potential of anterior cervical plates in multilevel corpectomies. Spine 24:2219-2223, 1999

17. Jung A, Schramm J, Lehnerdt K, Herberhold C: Recurrent laryngeal nerve palsy during anterior cervical spine surgery: A prospective study. J Neurosurg Spine 2(2):123-127, 2005

18. Jung-Ju H, Lih-Huei Chen, Chi-Chien N, Po-Liang L, Tsai-Sheng F, Wen-Jer C: Anterior cervical spinal surgery for multilevel cervical myelopathy. Chang Gung Med J 27(7):531-541, 2004

19. Koc RK, Menku A, Akdemir H, Tucer B, Kurtsoy A, Oktem IS: Cervical spondylotic myelopathy and radiculopathy treated by oblique corpectomies without fusion. Neurosurg Rev 27: 252-258, 2004

20. Kojima T, Waga T: Anterior cervical vertebrectomy and interbody fusion for multilevel spondylosis and ossification of the posterior longitudinal ligament. Neurosurgery 24:864-871, 1989

21. Lesion F, Bouasakao N, Clarisse J, Rousseaux M, Jomin M: Results of surgical management of radiculomyelopathy caused by cervical arthrosis based on 1000 operations. Surg Neurol 23: 350-355, 1985
22. Lu j, Wu X, Li Y, Kong X: Surgical results of anterior corpectomy in the aged patients with cervical myelopathy. Eur Spine J 17:129135,2008

23. Mann KS, Kholsa VK, Gulati DR: Cervical spondylotic myelopathy treated by single-stage multilevel anterior decompression. J Neurosurg 60: 80-87, 1984

24. Matsumoto $M$, Toyama $Y$, Ishikawa $M$, Chiba K, Suzuki N, Fujimura $Y$ : Increased signal intensity of the spinal cord on magnetic resonance images in cervical compressive myelopathy. Does it predict the outcome of conservative treatment. Spine 25(6): 677682,2000

25. McCormack BM, Weinstein PR: Cervical spondylosis: An update. Vest J Med 165:43-51, 1996

26. Montgomery DM, Brower RS: Cervical spondylotic myelopathy. Clinical syndrome and natural history. Orthop Clin North Am 23(3):487-493, 1992

27. Naderi S: Servikal spondilotik myelopatide cerrahi seçim. Türk Nöroşirürji Dergisi 10: 137-143, 2000 (In Turkish)

28. Naderi S, Benzel EC, Baldwin NG: Cervical spondylotic myelopathy: Surgical decision-making. Neursurg Focus 6:1, 1996

29. Nishihara N, Tanab G: Surgical treatment of cervical spondylotic myelopathy complicating athetoid cerebral palsy. J Bone Joint Surg 66: 504-508, 1984

30. Ng SC, Weiss JB, Quennel R, Jayson MI: Abnormal connective tissue degrading enzyme patterns in prolabsed intervertebral discs. Spine 11:695-701, 1986

31. Oh MC, Zhang HY, Park JY, Kim KS: Two-level anterior cervical discectomy versus one-level corpectomy in cervical spondylotic myelopathy. Spine 34(7): 692-696, 2009

32. Rowland LP: Surgical treatment of cervical spondylotic myelopathy: Time for a controlled trial. Neurology 42:5-13, 1992

33. Stewart TJ, Schlenk RP, Benzel EC: Multiple level discectomy and fusion. Neurosurgery 60(11):143-148, 2007

34. Teresi LM, Lufkin RB, Reicher MA, Moffit Bj, Vinuela FV, Wilson GM, Bentson JR, Hanafee WN: Asymptomatic degenerative disk disease and spondylosis of the cervical spine: MR imaging. Radiology 164:83-88, 1987

35. Whitehill R, Moran DJ, Fechner RE, Ruch WW, Drucker S, Hooper WE, McCoig JA: Cervical ligamentous instability in a canine in vivo model. Spine 12: 959-63, 1987

36. Wilkinson $\mathrm{M}$ : Cervical spondylosis: Its early diagnosis and treatment. 2nd ed. Philadelphia: WB Saunders, 1971

37. Witwer BP, Trost GR: Cervical spondylosis: Ventral or dorsal surgery. Neurosurgery 60(11):130-136, 2007

38. Yamashita Y, Kuroiwa Y: Cervical radiculomyelopathy caused by cerebral palsy (dystonic type): Clinical evaluation of our 10 cases. Shasishin Igaku 34: 293-297, 1979

39. Yamazaki T, Yanaka K, Sato H: Cervical spondylotic myelopathy: Surgical results and factors affecting outcome with special reference to age differences. Neurosurgery 52: 122-126, 2003

40. Yukawa Y, Kato F, Yoshihara H, Yanase M, Ito K: MR T2 image classification in cervical compression myelopathy: Predictor of surgical outcomes. Spine 32(15):1675-1678, 2007 